\title{
El inhibidor de la cinasa Bcr-Abl, STI 571, un ejemplo de terapia del cáncer basada en blancos moleculares
}

\author{
Luis Alberto Gómez \\ Laboratorio de Fisiología Molecular, Instituto Nacional de Salud, Bogotá, D.C., Colombia.
}

Todos los cánceres estudiados tienen alteraciones y rearreglos en el ADN (ácido desoxirribonucleico) y cambios en la expresión y actividad de genes que regulan la proliferación y diferenciación celular $(1,2)$. A través del ciclo de vida, las células del cuerpo humano son expuestas a diversos factores físicos, químicos y biológicos, experimentan interacciones con otras células, hormonas y factores de crecimiento y pueden sufrir errores en la replicación del ADN. Ocasionalmente, estos factores promueven el crecimiento celular, inducen cambios en la actividad de algunos genes o provocan mutaciones que pueden ocasionar la pérdida o inactivación de genes críticos, lo cual resulta en un clon celular con mayores ventajas de crecimiento (2). Con cambios adicionales en proteínas específicas o en otros genes críticos, estas células se expanden, invaden el tejido y pueden llegar a hacer metástasis (1-3). Existen muchos tipos de alteraciones y rearreglos genéticos que se presentan en las células cancerosas tales como grandes y pequeñas pérdidas o deleciones de material genético, mutaciones puntuales, sustituciones, inserciones pequeñas, amplificaciones y cambios epigenéticos como la metilación (1). Es así como el cáncer es la enfermedad genética más común: una de cada tres personas en el mundo occidental desarrollan cáncer y una de cada cinco mueren por esta causa. Por tanto, la identificación de los genes, sus productos y sus funciones (blancos moleculares) causantes de oncogénesis (transformación maligna) son algunos de los objetivos centrales de la investigación actual en cáncer.

\section{Correspondencia:}

Igomez@hemagogus.ins.gov.co

Recibido:18/05/01; aceptado: 8/06/01
Algunos rearreglos genéticos que resultan en la pérdida de genes supresores de cáncer o en la activación de oncogenes (genes productores de cáncer), se pueden originar como resultado de translocaciones cromosómicas (cambio de posición por ruptura y fusión de fragmentos de cromosomas). Este tipo de anormalidades son comunes en leucemias, linfomas y sarcomas y, frecuentemente, resultan en la formación de una molécula quimérica, es decir, un producto de un gen, resultado de la fusión de porciones de dos genes diferentes, aunque en algunos casos la translocación simplemente resulta en la desregulación de un gen intacto (4). En la leucemia mieloide crónica (LMC), un cáncer de la sangre caracterizado por la excesiva proliferación de células de linaje mieloide, la alteración citogenética más conspicua es la presencia del cromosoma Filadelfia, el cual se origina de la translocación recíproca entre los cromosomas 9 y 22 (5). La consecuencia molecular de esta translocación es el reemplazo del primer exón del protooncogén c-Abl (este nombre se deriva de la homología del gen humano con el oncogén del virus de la leucemia murina de Abelson) con secuencias del gen Bcr, que resulta en un gen de fusión BCR-ABL, cuyo producto proteico tiene una actividad tirosina-cinasa incrementada $(6,7)$. La oncoproteína Bcr-Abl en la LMC es una proteína de 210 kilodaltons (p210), que se encuentra en el $95 \%$ de pacientes con LMC y en el 5 a $10 \%$ de pacientes adultos con leucemia aguda y no se encuentra en células normales. Ratones transfectados con esta proteína desarrollan LMC y para que se produzca, se requiere que la actividad cinasa de p210 Bcr-Abl esté elevada $(8,9)$.

Las cinasas son una gran familia de proteínas que hacen parte funcional de varias vías de 
señalización intracelular reguladoras del crecimiento celular, la diferenciación, el metabolismo, la adhesión, la movilidad y la muerte celular, procesos que están alterados en el cáncer. Al inhibir selectivamente su actividad en células tumorales, se puede lograr el control de su crecimiento, por ejemplo, en LMC $(9,10)$. La investigación de inhibidores de proteínas cinasas selectivas que puedan bloquear o modular enfermedades con anormalidades en estas vías de señalización es una de las aproximaciones promisorias para el desarrollo de drogas antitumorales. Basados en la clara asociación entre el cromosoma Filadelfia, la tirosina-cinasa Bcr-Abl y la LMC, p210 Bcr-Abl fue identificada como una enzima eficaz para validar la utilidad clínica de inhibidores de proteínas cinasas. Habiendo identificado la proteína Bcr-Abl como un apropiado blanco molecular, la siguiente tarea fue diseñar un inhibidor específico de esta enzima $(10,11)$. Uno de los primeros inhibidores fueron los derivados de 2-fenil-amino pirimidinas y, de allí, se derivó un inhibidor muy potente que se llamó ST1 571 (inicialmente CGP J7148B). En LMC el compuesto STI 571 inhibe la actividad de la proteína tirosina-cinasa Bcr-Abl y de la proliferación de estas células; los estudios clínicos fase II, que se iniciaron en junio de 1998 con pacientes con $L M C$ resistente al tratamiento con interferón, han proporcionado resultados muy alentadores en el tratamiento de esta leucemia (11). El tratamiento con STI 571 se administra como terapia oral diaria. Los efectos colaterales han sido mínimos y no se ha encontrado toxicidad, incluso a dosis altas. A dosis de 300 miligramos o mayores, todos los pacientes han alcanzado respuesta hematológica completa y también se ha observado respuesta citogenética. Los estudios preclínicos se correlacionan bien con las respuestas clínicas en $\operatorname{LMC}(10,11)$.

Recientes estudios preclínicos sugieren el potencial uso clínico de este tipo de drogas (Inhibidores de cinasas) en el tratamiento de otras enfermedades y cánceres que involucren la actividad anormal de tirosina-cinasas y serinatreonina cinasas, como podría ocurrir en diversas formas de cáncer de estómago y de seno, entre otros (12). Sin embargo, se requieren más trabajos de investigación preclínicos y, luego, clínicos antes que el inhibidor STI $571 \mathrm{u}$ otros inhibidores puedan demostrar su utilidad en el tratamiento de otras formas de cáncer. Curiosamente, el patrón de oncogénesis observado en LMC, en el cual la translocación entre el cromosoma 9 y 22 es suficiente para la generación de este cáncer, no ha sido documentado frecuentemente entre muchos de los cánceres epiteliales más comunes de personas adultas. Si estos rearreglos existen pero están ocultos en la complejidad y desorganización del genoma de células cancerosas epiteliales o si, simplemente, no están presentes o son muy poco frecuentes, es tema de investigación actual.

Debido a la desregulación de proteínas cinasas en cánceres humanos, las proteínas cinasas $C$ (PKC), Bcr-Abl, EGFR y HER2 fueron algunas de las primeras cinasas consideradas como blancos moleculares para el desarrollo de inhibidores específicos. A medida que nuevas cinasas han sido implicadas en el desarrollo y progresión del cáncer, un campo de intenso estudio en la actualidad, se están investigando nuevos inhibidores. El uso de inhibidores de proteínas cinasas en otros cánceres es esperanzador; sin embargo, se requiere más tiempo para conocer su real alcance y, sobre todo, más investigación de los blancos moleculares apropiados en otras formas de cáncer. En este contexto, en el Laboratorio de Fisiología Molecular del INS estamos investigando potenciales blancos moleculares implicados en carcinogénesis y en metástasis, proceso éste de diseminación e invasión de células cancerosas a otros tejidos. Basados en la expresión diferencial de varios genes en forma simultánea (13), uno de los objetivos es identificar blancos moleculares involucrados en la re-adquisición del control del crecimiento celular y en la pérdida del potencial metastásico (3). Resultados preliminares indican que existen cinasas y fosfatasas (enzimas con una actividad opuesta a las cinasas) específicas que pueden estar implicadas en el crecimiento, viabilidad y movilidad celular necesarios para que la célula tumoral haga metástasis (datos no publicados). Con esta información, pretendemos desarrollar estrategias terapéuticas molecularmente 
dirigidas, de manera análoga con lo encontrado en LMC. El logro de la inhibición farmacológica del crecimiento tumoral y de la metástasis en forma selectiva representaría un abordaje ventajoso en comparación con la destrucción celular indiscriminada inducida por la quimioterapia y radioterapia convencionales.

La existencia de un gran número de blancos moleculares potenciales, los cuales se incrementarán con el avance en el estudio del genoma humano, permite anticipar que el hallazgo del inhibidor STI 571 será uno de los primeros ejemplos de una terapéutica basada y orientada por las investigaciones en la anatomía y fisiología molecular de células tumorales (14).

\section{Referencias}

1. Ponder BAJ. Cancer genetics. Nature 2001;411:336-41.

2. Hanahan D, Weinberg RA. The hallmarks of cancer. Cell 2000;100:57-70.

3. Gómez LA, Strasberg MR, Rieber M. Decrease in actin gene expression in melanoma cells compared to melanocytes is partly counteracted by $\mathrm{BrdU}$-induced cell adhesion and antagonized by L-Tyrosine induction of terminal differentiation. Biochem Biophys Res Comm 1995;216:84-9.

4. Rowley JD. The critical role of chromosome translocations in human leukemias. Ann Rev Genet 1998; 32:495-519.

5. Bartram CR, de Klein A, Hagemeijer A, van Agthoven T, Geurts van Kessel A, Bootsma D, et al. Translocation of $\mathrm{c}$-abl correlates with the presence of a Philadelphia chromosome in chronic myelocytic leukemia. Nature 1983;306:277-80.
6. Ben-Neriah Y, Daley GQ, Mes-Masson, Witte ON, Baltimore D. The chronic myelogenous leukemiaspecific $\mathrm{p} 210$ protein is the product of the bcr/abl hybrid gene. Science 1986; 986:212-4.

7. Konopka JB, Watanabe, SM, Witte ON. An alteration of the human c-abl protein in K562 unmasks associated tyrosine kinase activity. Cell 1984;37:1035-42.

8. Kurzrock R, Gutterman JU, Talpaz M. The molecular genetics of Philadelphia chromosome-positive leukemias. N Engl J Med 1988;319:990-8.

9. Hanks S K, Hunter T. Protein kinases: the eukaryotic protein kinase superfamily: kinase (catalytic) domain structure and classification. FASEB J 1995;9:576-96; Biol 1994;5:367-76.

10. Buchdunger E, Zimmermann J, Mett H, Meyer T, Muller M, Druker BJ, et al. Inhibition of the Abl proteintyrosine kinase in vitro and in vivo by a 2phenylaminopyrimidine derivative. Cancer Res 1996;56: 100-4.

11. le Coutre P, Mologni L, Cleris L, Marchesi E, Buchdenger E, Giardini R, et al. In vivo eradication of human BCR/ABL-positive leukemia cells with an $A B L$ kinase inhibitor. J Natl Cancer Inst 1999;91:163-8.

12. Wedge SR, Ogilvie DJ, Dukes M, Kendrew J, Curwen JO, Hennequin LF, et al. ZD4190: an orally active inhibitor of vascular endothelial growth factor signaling with broad spectrum antitumor efficacy. Cancer Res 2000;60:970-5.

13. Gómez LA, Strasberg MR, Rieber M. PCR-mediated differential display and cloning of a melanocyte gene decreased in malignant melanoma and up-regulated with sensitization to DNA damage. DNA Cell Biol 1996;15: 423-7.

14. International Human Genome Sequencing Consortium. Initial sequencing and análisis of the human genome. Nature 2001;409:860-921. 